Institute of $\mathbf{F}_{\text {ood and }} \mathbf{A}_{\text {gricultural }} \mathbf{S}_{\text {ciences }}$

\title{
Living Actively for Good Health: My Action Plan ${ }^{1}$
}

Jennifer Hillan²

Physical activity is important for good health. And it's not limited to vigorous exercise classes or team sports!

Put a check next to the activities you do most days of the week and write down how long you do each activity. Then turn the page over to develop your personal plan for an active lifestyle.

Walking briskly

Climbing stairs

Bicycling

Dancing

Swimming

Jogging

Team sports

(basketball/volleyball)

Gardening/yard work (including mowing with a push mower) minutes

minutes

minutes

minutes

minutes

minutes

minutes

- minutes

minutes
Skipping rope

minutes

Active household chores minutes (vacuuming/mopping)

Roller blading or skating minutes

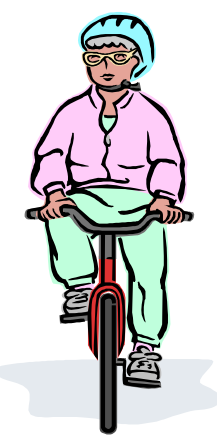

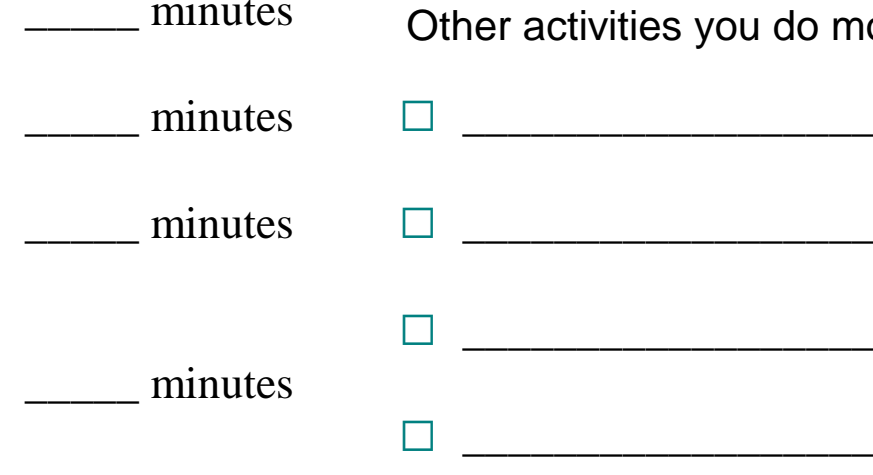

Total time: minutes minutes minutes minutes minutes

1. This publication is FCS8758-Eng, one of a series of the Department of Family, Youth and Community Sciences, Florida Cooperative Extension Service, Institute of Food and Agricultural Sciences, University of Florida. Publication date: August 2002. Reviewed by Isabel Valentín-Oquendo, MS, RD, LD/N, Department of Family, Youth and Community Sciences. Please visit the EDIS Web site at http://edis.ifas.ufl.edu

2. Jennifer Hillan, MSH, RD, LD/N, coordinator, Educational/Training Programs, Department of Family, Youth and Community Sciences, Cooperative Extension Service, Institute of Food and Agricultural Sciences, University of Florida, Gainesville, 32611. 
For good health, we should be active at least 30 minutes most days of the week. If you met that goal, congratulations! If not, how can you improve your physical activity level?

Make a plan to improve your health by checking the activities you'll do most days of the week. Then write down how long you will do each activity.
Be realistic! If you are currently inactive, start slowly with one or two activities for 5 or 10 minutes. You can gradually increase your time later.
Walking briskly

Climbing stairs

Bicycling

Dancing

Swimming

Jogging

Team sports

(basketball/volleyball)

Gardening/yard work (including mowing with a push mower) minutes

minutes

minutes

minutes

minutes

minutes

minutes

minutes
Skipping rope

Active household chores (vacuuming/mopping)

Roller blading or skating Other activities you'll do most days of the week:

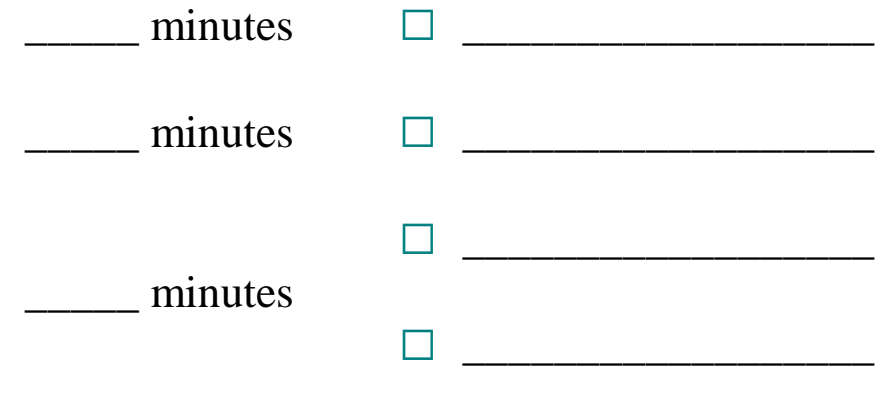

Total time: minutes minutes minutes minutes minutes minutes minutes

\section{If I reach my physical activity goal, I will reward myself by}

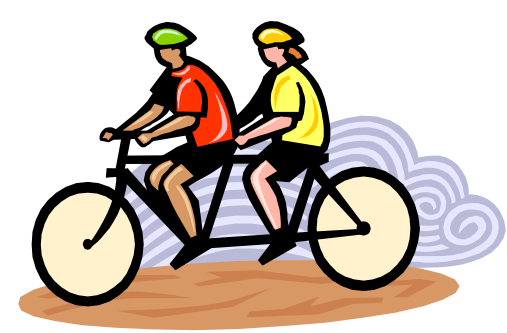

Talk with your health care provider before increasing your physical activity if:

- you are an inactive man over age 40 or inactive woman over 50 planning to start vigorous activity

- you have diabetes, heart disease, or another chronic health condition

- you are at high risk for heart disease 